\title{
Is Truth the Gold Standard of Inquiry? A Comment on Elgin's Argument against Veritism
}

\author{
Moti Mizrahi \\ Florida Institute of Technology
}

\begin{abstract}
In True Enough, Catherine Elgin (2017) argues against veritism, which is the view that truth is the paramount epistemic objective. Elgin's argument against veritism proceeds from considering the role that models, idealizations, and thought experiments play in science to the conclusion that veritism is unacceptable. In this commentary, I argue that Elgin's argument fails as an argument against veritism. I sketch a refutation by logical analogy of Elgin's argument. Just as one can aim at gold medals and still find approximations to gold, such as silver and bronze medals, to be acceptable and honest achievements in competitive sports, one can aim at full truths as the paramount epistemic objective and still find approximations to truth, such as models and idealizations, to be acceptable and honest achievements in scientific inquiry.
\end{abstract}

Keywords: Catherine Elgin; epistemic objective; scientific idealizations; truth; veritism

In True Enough, Catherine Elgin (2017, p. 9) argues that "Truth ought not be our paramount epistemic objective." In other words, Elgin argues against a "truth-centered epistemology" or veritism, which is the view that truth is the paramount epistemic objective. If "we accept [veritism]", Elgin (2017, p. 9) argues, "we cannot do justice to the epistemic achievements of science.”

Elgin's (2017, p. 11) argument against veritism proceeds from considering the role that models, idealizations, and thought experiments play in science to the conclusion that veritism is unacceptable. As Elgin (2017, p. 15) writes:

Far from being defects, models, idealizations, and thought experiments figure ineliminably in successful science. If truth is mandatory, much of our best science turns out to be epistemologically unacceptable and perhaps intellectually dishonest. Our predicament is this: We can retain the truth requirement and construe science either as cognitively defective or as noncognitive, or we can reject, revise, or relax the truth requirement and remain cognitivists about and devotees of science.

Since Elgin (2017, p. 15) takes it for granted that "science provides an understanding of the natural order," she concludes that we should reject veritism in order to "remain cognitivists about and devotees of science."1

Accordingly, Elgin's argument from scientific models, idealizations, and thought experiments against veritism can be stated as follows:

\footnotetext{
${ }^{1}$ One might complain that Elgin's argument against veritism applies to scientific inquiry in particular, not epistemic inquiry in general, since the examples she uses to support the premises of her argument against veritism come from science (e.g., the Ideal Gas Law) only. In this commentary, then, I restrict the discussion to scientific inquiry in particular.
} 
(1) If truth is the paramount epistemic objective of scientific inquiry, then scientific models, idealizations, and thought experiments are epistemologically unacceptable (because they are not entirely true).

(2) It is not the case that scientific models, idealizations, and thought experiments are epistemologically unacceptable (despite being not entirely true).

(3) It is not the case that truth is the paramount epistemic objective of scientific inquiry. ${ }^{2}$

Elgin has made a similar argument against veritism before, with a particular focus on scientific idealizations (emphasis added):

Explanations that adduce the ideal gas law would be epistemically unacceptable if abject fidelity to truth were required. Since helium molecules are not dimensionless, mutually indifferent, elastic spheres, an account that represents them as such is false. If veritism is correct, it is epistemically unacceptable. But, at least if the explanation concerned the behavior of helium in circumstances where divergence from the ideal gas law is negligible (roughly where temperature is high and pressure is low), scientists are apt to find it unexceptionable (Elgin 2004, p. 118).

Here, too, Elgin argues against veritism from the fact that scientific idealizations are epistemically acceptable in scientific inquiry. That is, if veritism were true, then scientific idealizations would be epistemically unacceptable in scientific inquiry. But scientific idealizations are epistemically acceptable in scientific inquiry. Therefore, veritism is not true. ${ }^{3}$

In this commentary, I will argue that Elgin's argument fails as an argument against veritism. I will sketch a refutation by logical analogy of Elgin's argument. If the analogy holds, then Elgin's argument against veritism fails to show that "Truth ought not be our paramount epistemic objective" in scientific inquiry (Elgin 2017, p. 9).

The analogy is as follows:

truths : scientific inquiry :: gold medals : Olympic Games

That is, in sports competitions, such as those that take place during the Olympic Games, the paramount objective of each athlete (or team of athletes) is to win gold medals. Not all athletes

\footnotetext{
${ }^{2}$ Cf. Nawar's (2019) reconstruction of Elgin's argument against truth-centered epistemology.

${ }^{3}$ For the purposes of this commentary, I am interested in Elgin's argument from approximations (e.g., scientific models and idealizations) against veritism only, not her further arguments for (non-factive) understanding as the paramount epistemic objective of (scientific) inquiry. Of course, Elgin must first show that truth is not the paramount epistemic objective of (scientific) inquiry before she can propose that (non-factive) understanding is the paramount epistemic objective of (scientific) inquiry; otherwise, she would be begging the question against those who think that the paramount epistemic objective of (scientific) inquiry is truth (see, e.g., Rowbottom 2008), or knowledge (see, e.g., Bird 2007), or anything else besides (non-factive) understanding (see, e.g., Niiniluoto 2014). Moreover, if Elgin were to assume that non-factive (scientific) understanding is the paramount epistemic objective of (scientific) inquiry as a premise in her argument against veritism, she would also be begging the question against those who think that understanding is factive (see, e.g., Grimm 2006) or quasi-factive (see, e.g., Mizrahi 2012). I am not suggesting that Elgin's argument from approximations against veritism is question-begging. In fact, as I have construed it, it says nothing about the paramount epistemic objective of scientific inquiry, except that it is not truth.
} 
(or teams of athletes) will win gold medals, of course, and so some have to be content with silver medals, bronze medals, or no medals at all. Nonetheless, it is still a great achievement to win a silver medal. It is also a great achievement to win a bronze medal. No athlete would argue that silver medals and bronze medals are unacceptable or dishonest achievements in competitive sports. Silver medals and bronze medals are acceptable and honest achievements in competitive sports; it's just that gold medals are even greater achievements.

By analogy, scientific models, idealizations, and thought experiments are epistemically acceptable and intellectually honest achievements in science, as premise (2) of Elgin's argument states. But it is still the case that truths are even greater epistemic achievements than scientific models, idealizations, and thought experiments, which are approximations or "felicitous falsehoods" as Elgin (2017, p. 29) calls them, insofar as truths are more accurate than approximations or useful falsehoods. In other words, one can aim at truth as the paramount epistemic objective and still find approximations or useful falsehoods, such as scientific models and idealizations, to be epistemically acceptable and intellectually honest achievements in scientific inquiry just as one can aim at gold medals as the paramount objective and still find approximations to gold, such as silver and bronze medals, to be acceptable and honest achievements in competitive sports. That is:

models/idealizations : scientific inquiry :: silver/bronze medals : Olympic Games

Accordingly, to argue that truth is not the paramount epistemic objective of scientific inquiry because we find things that are less than fully true (namely, scientific models and idealizations) to be epistemically acceptable and intellectually honest achievements in scientific inquiry is like arguing that gold medals are not the paramount objective of competitive sports because we find things that are less than fully gold (namely, silver and bronze medals) to be acceptable and honest achievements in competitive sports. If the argument fails in the context of Olympic sports, which it clearly does, then it fails in the context of scientific inquiry as well. ${ }^{4}$

If this is correct, then Elgin's argument from approximations against veritism fails to show that veritism is unacceptable. Just as one can find silver and bronze medals to be acceptable and honest achievements while aiming at gold medals as the paramount objective in Olympic sports, one can find approximations to truth and useful falsehoods to be epistemically acceptable and intellectually honest achievements while still aiming at truth as the paramount epistemic objective in scientific inquiry. Accordingly, my refutation by logical analogy of Elgin's argument from approximations against veritism can be summed up as follows:

(1) If truth is not the paramount epistemic objective of scientific inquiry because approximations to truth (i.e., scientific models and idealizations) are acceptable and honest achievements in science, then gold medals are not the paramount objective of

\footnotetext{
${ }^{4}$ From reading her (1993), one might get the impression that Elgin would argue that pictures pose a special problem for veritism, since they are not the sort of things that can be bearers of truth. As Elgin herself writes in her (2017), however, pictures, like models, are representations. As such, they can be more or less accurate. As Elgin (2017, p. 251) writes, "Pictures, equations, graphs, charts, and maps represent their subjects by denoting them. They are representations of the things they denote. It is in this sense that scientific models represent their target systems: they denote them." Being representations just as models are, then, it seems that, for Elgin, pictures do not pose a special problem for veritism (any more than scientific models and idealizations already do).
} 
Olympic sports because approximations to gold medals (i.e., silver and bronze medals) are acceptable and honest achievements in competitive sports.

(2) It is not the case that gold medals are not the paramount objective of Olympic sports because approximations to gold medals (i.e., silver and bronze medals) are acceptable and honest achievements in competitive sports.

(3) It is not the case that truth is not the paramount epistemic objective of scientific inquiry because approximations to truth (i.e., models and idealizations) are acceptable and honest achievements in science.

If this argument is sound, then Elgin's argument from approximations fails to show that veritism is unacceptable. Just as scientific "models, idealizations, and thought experiments figure ineliminably in successful science" (Elgin 2017, p. 15), silver and bronze medals figure ineliminably in successful sports. In Olympic sports, silver and bronze medals are acceptable and honest achievements while gold medals are still the paramount objective. Similarly, in science, scientific models and idealizations could be acceptable and honest achievements while truths could still be the paramount epistemic objective. The mere fact that we deem some epistemic achievements of science that fall short of full truth epistemically acceptable and intellectually honest does not show that truth is not the paramount epistemic objective of science.

To this, it might be objected that there is a relevant dissimilarity between scientific approximations (such as scientific models and idealizations) and approximations in sports (such as silver and bronze medals). Scientific approximations play a crucial role in science, such that they make success in science possible, whereas approximations in sports do not, or so it might be argued. But this is not the case. Just as scientific models and idealizations play a crucial role in scientific inquiry, such that they make success in science possible, silver and bronze medals play a crucial role in competitive sports, such that they make success in Olympic sports possible. For an athlete (or a team) to be the most successful in a sports competition, and thereby worthy of a gold medal, there must be other athletes (or teams) who are less successful, and thereby worthy of silver or bronze medals, or no medals at all. Similarly, for a scientific model to be successful, there must be other models that are less successful than it. After all, the evaluation of competing models in science, just like the evaluation of competing athletes (or teams) in sports, is comparative: one is more or less successful in comparison to others. ${ }^{5}$ As Wray $(2018$, p. 4) puts it, "when scientists are choosing a theory [or a model], they are seldom choosing between more than a few competing theories [or models] and [...] their evaluations of competing theories [or models] are comparative in nature." In that respect, just as scientific "models, idealizations, and thought experiments figure ineliminably in successful science" (Elgin 2017, p. 15), silver and bronze medals figure ineliminably in successful sports. In competitive sports, silver and bronze medals are acceptable and honest achievements although gold medals are still the paramount objective. Similarly, scientific models and idealizations could be epistemically acceptable and intellectually honest achievements although truths could still be the paramount epistemic objective of scientific inquiry.

It might also be objected that there is another relevant dissimilarity between approximations in science and approximations in sports. Sometimes an approximation or a useful falsehood may be

${ }^{5}$ On comparative theory evaluation in science, see Lipton (1993), Wray (2012), and Mizrahi (2013). 
better than accurate models or true theories, whereas gold medals are always better than silver and bronze medals. As Elgin (2017, p. 30) puts it, an approximation or a useful falsehood "may make cognitive contributions that the unvarnished truth cannot match." Elgin $(2017$, p. 30) gives the example of "a first-order partial differential equation" that "describes how air flows directly over an airplane wing," but "does not admit of an analytic solution," and claims that, in this case, the "approximation [...] is more fruitful than the truth" insofar as it "can serve as evidence for or constraints on future inquiry." If approximations or useful falsehoods can be better than truths in terms of being "fruitful," i.e., "serving as evidence for or constraints on future inquiry" (Elgin 2017 , p. 30), then the same can be said about approximations in sports. For instance, if it impossible for an athlete to win a silver medal in the 2020 Olympic Games, and so she has to be content with a bronze medal, this achievement can then serve as a guide to future competitions. That is, from her achievement in the 2020 Olympic Games, our athlete can learn what she needs to do in order to win a silver medal in the 2022 Olympic Games. Winning a bronze medal can also help our athlete land endorsements, sponsorships, and contracts that winning a gold medal might not be able to, which would then put her in a better position to win a silver medal in the 2022 Olympic Games. In that sense, winning a bronze medal could be more fruitful than winning a gold medal, just as "a first-order partial differential equation that approximates the truth, but admits of an analytical solution," is more fruitful than "a second-order partial differential equation that exactly describes fluid flow in a boundary layer," but that "no one knows how to solve" (Elgin 2017, p. 30).

More importantly, none of this would change the fact that winning a gold medal would still be the paramount objective of our athlete. Her achievement in the 2020 Olympic Games might be more fruitful for her insofar as it could land her endorsements, sponsors, and the like. But she would still aim to win a gold medal the next time she competes in the Olympic Games. In other words, the fact that a bronze medal was more fruitful than a gold medal for our athlete does not show that her paramount objective was not to win gold medals. Similarly, the fact that an approximation or useful falsehood was more fruitful than an exact equation for "fluid dynamicists" (Elgin 2017, p. 30) does not show that their paramount objective was not to find an exact equation. So truth can still be the paramount epistemic objective in scientific inquiry, even if approximations or useful falsehoods can sometimes be more fruitful than exact equations, accurate models, or true theories. If this is correct, then the analogy still holds. In competitive sports, silver and bronze medals are acceptable and honest achievements, which can sometimes be preferable to golds medals, and yet gold medals are still the paramount objective. Similarly, scientific models and idealizations could be acceptable and honest achievements, which can sometimes be preferable to accurate models and true theories, and yet truths could still be the paramount epistemic objective of scientific inquiry. So, again, from the mere fact that we deem some epistemic achievements of science that fall short of full truth epistemically acceptable and intellectually honest it does not follow that truth is not the paramount epistemic objective of science.

\section{Acknowledgements}

I am very grateful to three anonymous reviewers of Foundations of Science for their helpful comments on earlier drafts. 


\section{References}

Bird, A. (2007). What Is Scientific Progress? Nô̂s 41 (1): 92-117.

Elgin, C. Z. (1993). Understanding: Art and Science. Synthese 95 (1): 13-28.

Elgin, C. Z. (2004). True Enough. Philosophical Issues 14 (1): 113-131.

Elgin, C. Z. (2017). True Enough. Cambridge, MA: The MIT Press.

Grimm, S. R. (2006). Is Understanding a Species of Knowledge? The British Journal for the Philosophy of Science 57 (3): 515-535.

Lipton, P. (1993). Is the Best Good Enough? Proceedings of the Aristotelian Society 93 (1): 89104.

Mizrahi, M. (2012). Idealizations and Scientific Understanding. Philosophical Studies 160 (2): 237-252.

Mizrahi, M. (2013). The Argument from Underconsideration and Relative Realism. International Studies in the Philosophy of Science 27 (4): 393-407.

Nawar, T. (2019). Veritism Refuted? Understanding, Idealization, and the Facts. Synthese. https://doi.org/10.1007/s11229-019-02342-2.

Niiniluoto, I. (2014). Scientific Progress as Increasing Verisimilitude. Studies in History and Philosophy of Science Part A 75: 73-77.

Rowbottom, D. P. (2008). N-rays and the Semantic View of Progress. Studies in History and Philosophy of Science Part A 39 (2): 277-278.

Wray, K. B. (2012). Epistemic Privilege and the Success of Science. Nô̂s 46 (3): 375-385.

Wray, K. B. (2018). Resisting Scientific Realism. Cambridge: Cambridge University Press. 